\title{
An Empirical Study of C-E Soft News Translation Based on the Approach to Translation as Adaptation and Selection: With the Rendition of Soft News in Jinri Zhongguo as an Exemplar*
}

\author{
Wenpeng Lü \\ College of Foreign Language and Literature, Northwest Normal University, Lanzhou, China \\ Email: lvwpnwnu@163.com \\ Fuxin Ma \\ College of Foreign Language and Literature, Tianshui Normal University, Lanzhou, China \\ Email: mfx1977@163.com \\ Jing Wang \\ College of Foreign Language and Literature, Northwest Normal University, Lanzhou, China \\ Email: wangjing0229@21cn.com
}

\begin{abstract}
With the rendition of soft news in Jinri Zhongguo as an exemplar, the present study concerns C-E soft news translation based on the Approach to Translation as Adaptation and Selection by contrastive analysis of texts, investigation of recognition degree for the expected versions and interview of translators. The results show that the more effective strategy of soft news translation is adaptation, and the corresponding major method is communicative and the minor one is semantic. Translation process of soft news is the translator's adaption to the typically important components of "source text and target language" in one translation eco-environment and the selection of target text made by the typically important component of "translator" in the other. The translation ideology and method are influenced by translators' experiences of translation, understanding of source text, knowledge of text functions, etc. There is a correlation between the "degree of holistic adaptation and selection" of soft news versions and the "recognition degree of readers". Generally a better version has a higher "degree of holistic adaptation and selection" and higher "recognition degree of readers".
\end{abstract}

Index Terms-C-E soft news translation, the Approach to Translation as Adaptation and Selection, empirical study

\section{INTRODUCTION}

Soft news is seeking the positive effect of publicity, i.e. it highlights its readability, appeals to readers and emphasizes human touch and affection (Fang, 2002). The translation of soft news is not only the transformation between languages, but the communication between Chinese and Western cultures. Therefore, it is worthwhile studying how to translate soft news effectively. Entering the new century, China's soft news translation studies have showed science-oriented change moving from empiricism to scientism. Scholars (such as Xu \& Wang, 2001) study the translation of soft news by applying German Functionalist Theory, Pragmatic Theory, Communication Theory, etc. and have described and explained the process and methods (especially the adaptation) of soft news translation. These studies not only provide the methodological enlightenment from a scientific perspective but lay a solid foundation for us to put the soft news translation into a broader context. However, they are far from enough. On the one hand these theories still lack the support of empirical studies, on the other these macro-theories do not pay enough attention to the differences and complexity of micro-consciousness.

Guided by Darwin's Theory of Evolution the Approach to Translation as Adaptation and Selection (hereinafter referred to ATAS) makes a fresh description and interpretation of the translation nature, process, standards, principles and methods (Hu, 2008a). Professor Hu claims that translation, which is translator-centered, is the translator's adaption to the typically important component of "source text" in one translation eco-environment and the selection of target text made by the typically important component of "translator" in the other. In short, translation is adaptation and selection.

\footnotetext{
* Research supported by the "the Project of 'Eleventh Five-Year Plan' of Education Science in Gansu Province" (GSBG[2009]GX063), the "Core Project for Enhancing the Research Capability of Young Teachers in Northwest Normal University (Humanities and Social Science)" (SKQNGG10014) and the "Project of Teaching Research in 2011 in Northwest Normal University" (2011050B).
} 
Accordingly, the generation of target text can be divided into two phrases: the translation eco-environment selecting the translator and doing the target text (see Figure 1). The best version is the cumulative result of translator's adaptation and selection to the translation eco-environment. In other words, a better version has a higher "degree of holistic adaptation and selection (Hu, 2008a). The Approach provides a fresh perspective for the news translation.

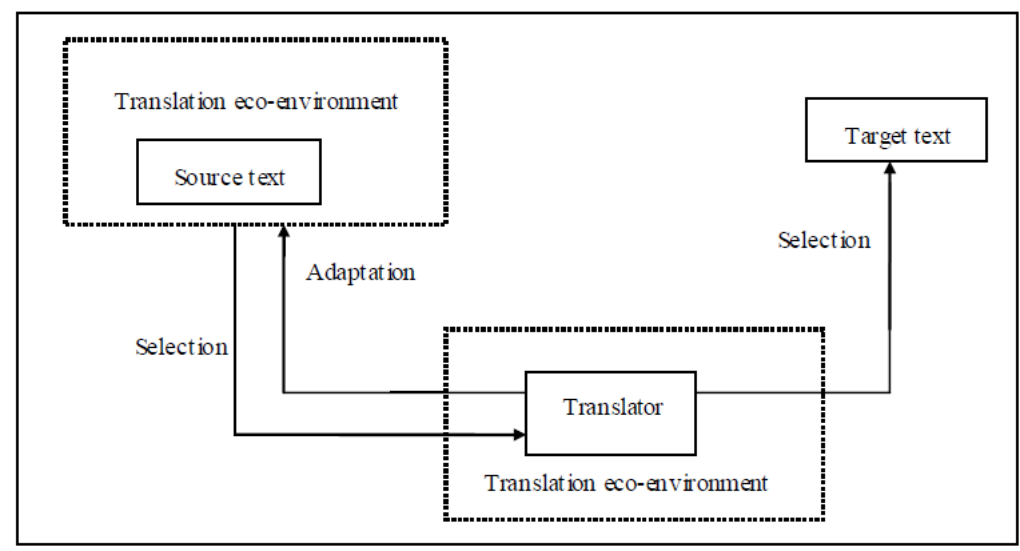

Figure 1 The translation process of "adaptation" and "selection" (Hu, 2008b: 92)

\section{The Application of the Approach to Translation as Adaptation and Selection to the Study of Soft NEWS TRANSLATION}

Jinri Zhongguo (China Today in English), a news-oriented monthly with vivid pictures, appeals to both refined and popular tastes. The readers of its Chinese version are people from Hong Kong, Macao, Taiwan and overseas Chinese, while those of its English version are foreign employees (in the field of business, technology, media, culture and education) and housewives. Taking the above literature review into account and aiming at exploring the effective methods of translating soft news, the present authors conduct an empirical research on the translation eco-environment of soft news based on ATAS. Taking a piece of soft news from China Today as an exemplar the paper adopts research methods as contrastive analysis of versions, investigation of the recognition degree for the expected versions and interview of translators.

\section{A. Investigation}

The soft news "Dao Nantong" (Wu \& Li, 2009) from Jinri Zhongguo vividly describes the geography, history and culture of Nantong, a famous city in Jiangsu Province, by picturing its typical attractions such as the Haohe River, the Langshan Mountain, the Shuihui Garden and Yuantuojiao. The author heightens the artistic effect with relaxed tone, elegant words and extravagant syntax. The English version (Wu, 2009) of it is from a Chinese professional translator (i.e. Translator 1, female, whose version is called Version 1). In order to contrast different versions, the authors invited a student translator (i.e. Translator 2, a freshman postgraduate majoring in translation studies), who translated the soft news (i.e. Version 2) without reading Version 1. Version 3 is the authors' version by applying ATAS. Later, the authors separately interviewed Translators 1 and 2 by telephone or QQ to discuss the problems in the C-E translation of this soft news. To further verify the influence of applying ATAS on the soft news translation, the authors conducted a questionnaire to learn the recognition degree (RD hereunder) for the expected version from the perspective of reader feedback and professional response. The questionnaire is mainly made up of subject's personal information and 8 typical translation cases from "Dao Nantong" and its English version. 29 subjects answered the questionnaire, including 4 American teachers (1 male and 3 females), 1 Chinese (male) studying for his doctorate in the USA and 24 postgraduates ( 1 male and 2 females in their first year, and 2 males and 19 females in their second year) majoring in English. Each subject was required to choose the best version by making a brief comment. The corresponding English questionnaire was used for American teachers. The result of the survey is shown in Table 1.

TABLE 1

SUBJECTS' RECOGNITION DEGREE (RD HEREUNDER) TO THE EXPECTED VERSIONS OF THE 8 CASES

\begin{tabular}{|c|c|c|c|c|c|c|c|c|c|}
\hline Translation Case & Case1 & Case 2 & Case 3 & Case 4 & Case 5 & Case 6 & Case 7 & Case 8 & $\begin{array}{l}\text { Weighted } \\
\text { Mean }\end{array}$ \\
\hline Expected Version & Version 1 & Version 1 & Version 3 & Version 1 & Version 3 & Version 1 & Version 1 & Version 1 & \\
\hline RD & $16 / 28$ & $20 / 29$ & $22 / 29$ & $25 / 29$ & $20 / 28$ & $17 / 29$ & $14 / 29$ & $22 / 28$ & \\
\hline ndex of Recognition Degree & 1.14 & 1.38 & 2.30 & 1.72 & 2.17 & 1.17 & 0.97 & 1.57 & 1.49 \\
\hline
\end{tabular}

Of the 8 translation cases, Case 1, 2, 4 and 6-8 have 2 versions and the probability of being selected is $50 \%$, while Case 3 and 5 have 3 versions and the probability is about 33\%. So the calculation is weighted. The baseline of Case 1, 2, 4 and 6-8 is 50\%, while that of Case 3 and 5 is 33\%. Thus, the weighted average baseline of the 8 translation cases is 
$45.75 \%$ (i.e. $6 / 8 \times 50 \%+2 / 8 \times 33 \%=45.75 \%$ ). The smaller the percentage is, the lower the RD is, and vice versa. As for Case 1, 2, 4 and 6-8, the RD is considered "general" when the percentage is $50 \%$; As for Case 3 and 5, the RD is regarded as "average" when the percentage is $33 \%$.

The average RD of Case 1, 2, 4 and 6-8 is $66.3 \%$, while that of Cases 3 and 5 is $73.65 \%$. Therefore, the weighted mean (WM hereunder) of RD to the expected version in the 8 translation cases is 68.14\% (i.e. $66.30 \% \times 6 / 8+73.65 \% \times 2 / 8=68.14 \%)$. Index of $\mathrm{RD}=\mathrm{RD} \div$ baseline. If the index of $\mathrm{RD}>1$, it means the RD is "good"; when the index of $\mathrm{RD}=1$, it means the $\mathrm{RD}$ is "average"; if the index of $\mathrm{RD}<1$, it means the RD is "deficient". The index of translation cases $1,2,4$ and $6-8=\mathrm{RD} \div 50 \%$ of the baseline, and its mean index of $\mathrm{RD}$ is 1.33 ; the index of Cases 3 and $5=\mathrm{RD} \div 33 \%$ of the baseline, and its mean index of RD is 2.24 . Of the translation cases $1-8$, the WM of RD to the expected translation is 1.49 (i.e. the WM of RD $68.14 \% \div$ baseline of the WM $45.75 \%=1.49$ ).

In Table 1, Version 3, which is translated by the authors based on ATAS, of Cases 3 and 5 is the expected one, whose index of RD is the highest 2.30 and 2.17 respectively. It indicates that the expected version of translation cases 3 and 5 have been highly accepted by the subjects. Version 1, which is translated by a professional translator taking into consideration the original information, the culture and readers of target language, is the expected of Cases $1,2,4$ and 6-8, whose index of $\mathrm{RD}>1$ indicating that the subjects have a higher $\mathrm{RD}$; while the index of $\mathrm{RD}$ of Case 7 is $0.97<1$ indicating that the subjects have a lower RD. Therefore, the authors make a further study on the collected questionnaires to analyze the RD of Case 7 and find out that, so far as the 4 American teachers and 1 Chinese studying for his doctorate in the US are concerned, its RD is $60 \%$, higher than the baseline (50\%); for the first-year postgraduates, its RD is 0 , lower than the baseline (50\%); for the second-year postgraduates, its RD is $57.14 \%$, also higher than the baseline (50\%). The statistics shows that the subjects' RD is affected by their educational background and their translation competence.

In a word, WM of RD to the expected version of Cases $1-8$ is $68.14 \%$, higher than the baseline of WM (45.75\%). The WM of the RD is $1.49>1$ indicating that subjects have a high RD to the expected version. In translating soft news, it is helpful and possible to generate better versions with higher degree of holistic adaptation and selection in case that the translators are guided by ATAS consciously or unconsciously.

\section{B. Analysis of Target Texts}

Aiming at discussing the effective method in translating soft news, 2 versions of "Dao Nantong" are studied with contrastive analysis, and the first 4 Cases in the questionnaire are analyzed.

1. Contrastive analysis of 2 versions

Soft news is an informative text (Newmark, 2001), whose transformation from linguistic and communicative dimensions are more important than that from cultural dimension (Hu, 2004). However, the function of discourses is rarely single, most of which have a major function and other minor ones (Newmark, 2001). In style "Dao Nantong" is close to a travel essay, which has both informative and vocative functions, indicating that its transformation from communicative and cultural dimensions is more important than that from linguistic one. What is common between source and target texts is that both aim at introducing and promoting Nantong, and stimulating the travelers' desire to travel to Nantong. The original text consists of 2 parts: Part 1(i.e. Paragraph 1-4) mainly introduces Nantong's history and its unique geography; Part 2 (i.e. Paragraph 5-29) displays Nantong's beautiful natural landscape and culture. Table 2 contrastively shows the differences between 2 versions in discourse structure, paragraph quantity, text function, translation strategies, translation methods, the degree of multidimensional transformation, the degree of holistic adaptation and selection, and reader feedback. 
TABLE 2

CONTRASTIVE ANALYSIS OF 2 VERSIONS

\begin{tabular}{|c|c|c|c|}
\hline $\begin{array}{l}\text { Contrastive } \\
\text { analysis }\end{array}$ & $\begin{array}{l}\text { Source } \\
\text { text }\end{array}$ & Version 1 & Version 2 \\
\hline Translator & & Professional translator, female & Student translator, female \\
\hline $\begin{array}{l}\text { Discourse } \\
\text { structure }\end{array}$ & $\begin{array}{l}2 \text { parts: } \\
\text { introductio } \\
\mathrm{n} \text { and body }\end{array}$ & $\begin{array}{l}3 \text { parts: introduction, body and } \\
\text { conclusion }\end{array}$ & 2 parts: introduction and body \\
\hline Paragraph quantity & 29 & 23 & $\begin{array}{l}28 \text { (Translator } 2 \text { only omits Paragraph } 18 \text { of } \\
\text { source text because she thinks it repetitive, and } \\
\text { the order of other paragraphs remain exactly } \\
\text { the same with the source text.) }\end{array}$ \\
\hline Text function & $\begin{array}{l}\text { Informativ } \\
\text { e and } \\
\text { vocative }\end{array}$ & Informative and vocative & Expressive and informative \\
\hline $\begin{array}{l}\text { Translation } \\
\text { strategy }\end{array}$ & & Adaptation & Complete translation \\
\hline $\begin{array}{l}\text { Translation } \\
\text { method }\end{array}$ & & $\begin{array}{l}\text { Communicative translation as the } \\
\text { primary and semantic translation as the } \\
\text { secondary }\end{array}$ & $\begin{array}{l}\text { Semantic translation as the primary and } \\
\text { communicative translation as the secondary }\end{array}$ \\
\hline $\begin{array}{l}\text { Degree of multi- } \\
\text { dimensional } \\
\text { transformation }\end{array}$ & & $\begin{array}{l}\text { The transformation from communicative } \\
\text { and cultural dimensions is more } \\
\text { important than that from linguistic one. } \\
\text { Translator } 1 \text { makes adaptive selection } \\
\text { not only from communicative, cultural } \\
\text { and linguistic dimensions, but from } \\
\text { other factors such as source text, target } \\
\text { language, length of writing, readers, } \\
\text { society, communicative channels and } \\
\text { client (employer). }\end{array}$ & $\begin{array}{l}\text { The transformation from linguistic dimension } \\
\text { is more important than that from } \\
\text { communicative and cultural ones. Translator } 2 \\
\text { makes adaptive selection mainly from the } \\
\text { linguistic dimension, and takes less } \\
\text { consideration of other factors such as culture, } \\
\text { communication, length of writing, readers, } \\
\text { society and communication channels. }\end{array}$ \\
\hline $\begin{array}{l}\text { Degree of holistic } \\
\text { adaptation and } \\
\text { selection }\end{array}$ & & Higher & Lower \\
\hline Reader feedback & & $\begin{array}{l}\text { With interesting adjectives but without } \\
\text { being too heavy or "flowery", Version } 1 \\
\text { is easily read and understood, which is } \\
\text { needed in an article designed for the } \\
\text { general public. It has a more natural } \\
\text { format and order, and the sentences are } \\
\text { shorter and to the point. }\end{array}$ & $\begin{array}{l}\text { Although it uses beautiful poetic language, } \\
\text { Version } 2 \text { tends to get "lost" in its descriptions. } \\
\text { Version } 2 \text { has many grammatical mistakes, too } \\
\text { many adjectives (and adjective clauses), and is } \\
\text { generally not easily read by a native speaker. It } \\
\text { might be a closer translation to what is really } \\
\text { said in Chinese, but most Americans write and } \\
\text { read very different texts. Version } 2 \text { seems as it } \\
\text { was translated by someone who is not as } \\
\text { familiar with translating a whole message, } \\
\text { rather than translating word-by-word. It is a } \\
\text { little cumbersome. Version } 2 \text { has very long } \\
\text { sentences that are not so common, and they are } \\
\text { harder to process and understand. }\end{array}$ \\
\hline
\end{tabular}

It is noteworthy that Translator 1 consciously divides the ending of the original text into 2 parts, thus forming the 3 rd part of the text - conclusion. It is chosen out of adapting the characteristics of the target language and target audience because the target audience is more accustomed to the classic rhetoric of "introduction, body and conclusion". Corresponding with the original text, Version 2 also has 2 parts and its translator does not consider the reading habits of the target audience. By the interview, the authors learn that Translator 1 completely deleted some unimportant information such as quoted poems and couplets to adapt the limited length of news and the acceptance characteristics of English readers, and to reduce their cognitive burden; on the contrary, Translator 2 thinks that information like quoted poems and couplets are essential for the original text, so she translates it fully. It is obvious that the choice of Translator 1 adapts more to the informative and vocative functions of the original text, embodying the choosing principle in news adaptation, which is supported by principles of "preservation of strong ones and elimination of weak ones" and "survival through selection". The two translators' differences in adaptation and selection lead to the different degree of acceptance to the target texts. 4 American subjects agree that Version 1 is better or clearer than Version 2. A foreign teacher comments, "While both use beautiful poetic language, Version 2 tends to get "lost" in its descriptions. I found myself having to re-read several paragraphs in order to understand meanings in Version 2. Additionally, Version 2 has quite a few incomplete sentences and several awkwardly worded sentences. Both versions have grammatical errors subject/verb agreement or verb consistency (using the same tense throughout a sentence) or incomplete sentences or the use of sentence fragments - but nothing too serious and nothing that an editor couldn't correct." News translation is an important channel in international communication and we must stick to the three close principles in publicity - close to the reality of Chinese development, close to the information needs of foreign audience and close to the thinking habit of foreign audience (Huang, 2004, p.27). In the translation process, Translator 1 adapts more to the target readers, to the delivery of news information and to the adaptation principle. So Version 1 has a higher degree of adaptation and selection than Version 2. 


\section{Contrastive analysis of translation cases}

\begin{tabular}{|l|l|}
\hline $\begin{array}{l}\text { Case 1: 到南通—听罢江 } \\
\text { 声听海声 }\end{array}$ & $\begin{array}{l}\text { Context: It is the title of the original text, highlighting the informative and vocative } \\
\text { functions of soft news concerning travel by using metonymies. }\end{array}$ \\
\hline Version 1: Travel to Nantong & $\begin{array}{l}\text { Analysis: Adapting the theme and cultural background of original text, Translator 1 selects } \\
\text { expressive forms and rhetorical styles of target language, which makes the English headline } \\
\text { short and concise, achieves the informative and vocative functions of original text and the } \\
\text { communicative purpose of source text's writer. }\end{array}$ \\
\hline $\begin{array}{l}\text { Version 2: People to Nantong } \\
\text { to listen to the sound of the } \\
\text { river and appreciate that of } \\
\text { the ocean }\end{array}$ & $\begin{array}{l}\text { Analysis: Literal translation is adopted. Being interviewed, Translator } 2 \text { said that while } \\
\text { selecting the target text, she had only considered how to adapt the source text but neglected } \\
\text { the target language's expressive characteristics and style, and the text function. One of the } \\
\text { US subject thinks it a little cumbersome and unnatural to English native speakers. It is hard } \\
\text { for Version 2 to achieve the ideal effects of international communication. }\end{array}$ \\
\hline $\begin{array}{l}\text { Review: As far as the title is concerned, Translator 1 makes better adaptation and selection and her expression is appropriate, } \\
\text { so the degree of holistic adaptation and selection of Version 1 is higher. The most highlighting feature of Version 1 judged by } \\
\text { the target audience is its conciseness and eye-catching. Version 2 is hard to understand because of many Chinglish } \\
\text { expressions in it. }\end{array}$
\end{tabular}

\begin{tabular}{|c|c|}
\hline $\begin{array}{l}\text { Case 2: 如果说中国乃至世界的版图多来自大地亿 } \\
\text { 万年某个抖动和怒吼, 当然, 也有的不过是大地酣 } \\
\text { 睡时不经意的一个懒腰, 如汶川现在的地貌, 唯有 } \\
\text { 长三角是个例外, 是千百年来长江和大海堆砌给人 } \\
\text { 类的礼物, 它们的前身, 都是时隐时现的水中沙洲。 } \\
\text { 南通, 便是沙洲之一, 一千多年前, 这里叫胡逗州。 }\end{array}$ & $\begin{array}{l}\text { Context: It's the first paragraph of the original text. Using } \\
\text { personification, metaphor and hyperbole, it vividly describes } \\
\text { Nantong's geographic features reflecting the exaggeration and spiral } \\
\text { thinking pattern of Chinese. With meaningful and emotional } \\
\text { expressions a great artistic momentum is heightened. }\end{array}$ \\
\hline $\begin{array}{l}\text { Version 1: Before silt from the Yangtze River and } \\
\text { Yellow Sea was deposited millennia ago into what is } \\
\text { now the Yangtze River Delta, the area had many tidal } \\
\text { sand ridges. Nantong, on the northern bank of the } \\
\text { Yangtze River's mouth in Jiangsu Province, was one of } \\
\text { these ridges, and 1,000 years ago was known as } \\
\text { Hudouzhou or Broad Bean Tidal Ridge. }\end{array}$ & $\begin{array}{l}\text { Analysis: From the perspective of Westerners' thinking pattern, } \\
\text { important information is often put at the end of a paragraph. } \\
\text { Keeping this in mind and adapting the communicative translation, } \\
\text { Translator } 1 \text { highlights the informative function of news text by } \\
\text { avoiding the empty and dwell on the full. Version } 1 \text { is clear, concise } \\
\text { and easy to understand, and it reduces the cognitive burden of } \\
\text { English readers, which is a selection based on adapting the } \\
\text { translation eco-environment presented by source text and original } \\
\text { and target languages. }\end{array}$ \\
\hline $\begin{array}{l}\text { Version 2: If the territory of China or even that of the } \\
\text { whole world originates from the earth's shakes or roars } \\
\text { billions of years ago, of course, some of which were } \\
\text { the earth's lazy casual stretch when it is sound sleep, } \\
\text { such as Wenchuan's now landscape, only the Yangtze } \\
\text { River Delta piled up by the Yangtze River and the sea } \\
\text { spending thousands of years as a gift to mankind is an } \\
\text { exception, its ultimate sources were the flickering } \\
\text { shoals surrounded by waters. Nantong is one of the } \\
\text { shoals, which was called Hudou County a thousand } \\
\text { years ago. }\end{array}$ & $\begin{array}{l}\text { Analysis: Translator } 2 \text { mechanically translates all the content of the } \\
\text { original text with pompous language. } \\
\text { A US subject comments, "Version } 2 \text { tries too hard to be poetic and } \\
\text { loses sight of what it is trying to communicate. The first sentence } \\
\text { is incomplete and rambles with several fragments strung together. } \\
\text { I feel the writer is trying to write a piece of great literature rather } \\
\text { than simply telling a story." This version only adapts to the vivid } \\
\text { description of the original text, but overlooks the main idea and } \\
\text { function of the original text, and the characteristics of target } \\
\text { language and target readers, so it achieves a lower degree of holistic } \\
\text { adaptation and selection. }\end{array}$ \\
\hline \multicolumn{2}{|c|}{$\begin{array}{l}\text { Review: The diffusive sentence pattern in the original text reflects subjective and fuzzy thinking way of oriental people. To } \\
\text { adapt the objective and precise thinking way of Westerners, translators should convert the diffusive sentences into compact } \\
\text { ones. Translator } 1 \text { effectively integrates dimensions of language, thinking, communication, etc. and considers stylistic features } \\
\text { of the soft news, which are straight to the point, concise and easy to understand. So Version } 1 \text { has been highly praised by } \\
\text { readers. Foreign teachers agree that Version } 2 \text { is hard to understand because of its vague and puzzling expressions. }\end{array}$} \\
\hline
\end{tabular}

It is obvious that flexible translation methods should be adopted in translating soft news, which is different from the hard news translation. Based on the full understanding of the original text, the translator must take into consideration the target readers' cognition, thinking and expressive features of target language to create a target text acceptable for target readers. If necessary, the translator could reorganize the target text by breaking the syntactic structure or expressive order in the original text, or only translate the important information based on the principle of "preservation of strong ones and elimination of weak ones". 


\begin{tabular}{|c|c|}
\hline $\begin{array}{l}\text { Case } 3 \text { : 其实一个病中之人能美到几 } \\
\text { 分, 然而张謇却日日守候在身边, 一笔 } \\
\text { 笔记录了沈寿口述的《雪宦绣谱》, 就 } \\
\text { 在张謇的印书局出版, 视为当今瑰宝。 }\end{array}$ & $\begin{array}{l}\text { Context: The sentence is taken from Paragraph } 14 \text { (Haohe section), whose } \\
\text { ending tells the love story between celebrities Zhang Jian and Shen Shou, an } \\
\text { embroidery master. }\end{array}$ \\
\hline Version 1: Omission. & $\begin{array}{l}\text { Analysis: Translator } 1 \text { states } 2 \text { reasons of omitting Paragraphs } 14 \text { and } 15 \text { in the } \\
\text { original text. One is that she rejects information unfamiliar and redundant for } \\
\text { target readers, and the other is the limited length of news. The translation } \\
\text { method is in line with the adaptation principle of news translation and also the } \\
\text { principle of "survival through selection". }\end{array}$ \\
\hline $\begin{array}{l}\text { Version 2: In fact, can't an ill person be } \\
\text { beautiful? However, Zhang Jian attended } \\
\text { her day and night, recording the Xue } \\
\text { Huan Embroidered Method in detail, } \\
\text { which was narrated orally by Shen Shou } \\
\text { and published in Zhang Jian's Press. } \\
\text { Now, we considered this book as our } \\
\text { national treasure. }\end{array}$ & $\begin{array}{l}\text { Analysis: Translator } 2 \text { faithfully converts the details of the original text, which } \\
\text { satisfies target readers' desire of learning foreign culture. A foreign teacher } \\
\text { wrote, "I like the detail of Version 2, but it is awkwardly worded. Here is how I } \\
\text { would reword Version } 2: \text { 'Even an ill person can be beautiful. Zhang Jian } \\
\text { attended her day and night, recording Shen Shou's detailed dictation of the Xue } \\
\text { Huan Embroidery Method, resulting in a book that to this day, is considered to } \\
\text { be a national treasure." " }\end{array}$ \\
\hline $\begin{array}{l}\text { Version 3: Her Book on the Art of } \\
\text { Embroidery, recorded while she was sick } \\
\text { in bed, and published by her lover, } \\
\text { Zhang Jian, is cherished even today. }\end{array}$ & $\begin{array}{l}\text { Analysis: The authors think that since Paragraphs } 12 \text { and } 13 \text { mainly describes } \\
\text { Shen Shou's skillful embroidery craft and its effects, it would lead to the } \\
\text { translation failure if Paragraphs } 14 \text { and } 15 \text { are deleted because it does not adapt } \\
\text { the communicative dimension of the original text. Since the former section has } \\
\text { introduced Zhang Jian, the reader can understand it if this part is translated. So } \\
\text { the authors put Case } 3 \text { at the end of Paragraph } 9 \text { and gets Version } 3 \text {. A Foreign } \\
\text { teacher thinks that Version } 3 \text { is clear, concise and easy to understand. }\end{array}$ \\
\hline
\end{tabular}

To achieve effectiveness and be accepted by target readers, translators must consider the receptive psychological factors of target readers, including their outlook on life, emotional attitude, knowledge structure, cultural background, cognitive way and expectation (Lu, 2002).

\begin{tabular}{|c|c|}
\hline $\begin{array}{l}\text { Case 4: 三百多年前, 明末四公子之一的 } \\
\text { 冒辟疆与秦淮八艳之一的董小宛, 就在水 } \\
\text { 绘园里把爱情浪漫到极致。 }\end{array}$ & $\begin{array}{l}\text { Context: Case } 4 \text { is from Paragraph } 23 \text { in the section of Shuihui Garden, which } \\
\text { focuses on the romantic love story between Mao Pijiang and Dong Xiaowan } \\
\text { happening in the Shuihui Garden. The important and hard point in translation is } \\
\text { the culturally-loaded words such as Mao Pijiang, Dong Xiaowan and Qinhuai } \\
\text { Bayan. }\end{array}$ \\
\hline $\begin{array}{l}\text { Version 1: The protagonist Mao Pijiang } \\
\text { (1611-1693) was a distinguished man of } \\
\text { letters in the late Ming and early Qing } \\
\text { dynasties. It was in this garden that Mao } \\
\text { started his romance with Dong Xiaowan, } \\
\text { one of the top eight geishas (beautiful } \\
\text { women of artistic versatility who were } \\
\text { trained from childhood to entertain } \\
\text { intellectuals and upper-class people) along } \\
\text { the Qinhuai River in the vicinity of } \\
\text { Jiangsu's Nanjing. }\end{array}$ & $\begin{array}{l}\text { Analysis: Translator } 1 \text { figures out the differences between source and target } \\
\text { languages and cultures, so literal translation and annotation method (underlined } \\
\text { part) are adopted to translate the information about Mao Pijiang, and free } \\
\text { translation and annotation method about Qinhuai Bayan, which highlights the } \\
\text { unique Chinese culture and makes a deep impression on the target readers, and } \\
\text { is helpful for cross-culture communication. The subjects think that "geisha" is a } \\
\text { keyword in Version 1, and although the sentence loaded the cultural } \\
\text { information of Qinhuai Bayan is too long, target readers could easily } \\
\text { understand it. }\end{array}$ \\
\hline $\begin{array}{l}\text { Version 2: More than } 300 \text { years ago, Mao } \\
\text { Pijiang and Dong Xiaowan, one of the } \\
\text { beauties of Qinhuai played their love to the } \\
\text { extreme on the Garden Shuihui. }\end{array}$ & $\begin{array}{l}\text { Analysis: Adopting word-by-word translation, expressions in Version } 2 \text { are } \\
\text { plain and deficient (such as "played their love"). Translator } 2 \text { fails in delivering } \\
\text { the cultural information of the original text. Some subjects say, "Although } \\
\text { Version } 2 \text { is similar to the original text, it is hard to understand for westerners } \\
\text { with little knowledge about Chinese culture". Paying little attention to the } \\
\text { differences between Chinese and Western cultures, Translator } 2 \text { fails in } \\
\text { completely adapting the target language environment. It is hard for Version } 2 \text { to } \\
\text { gain the same or similar effects among target readers as among the original } \\
\text { ones, so it can only convey limited cultural information to target readers. }\end{array}$ \\
\hline & $\begin{array}{l}\text { m the perspectives of language, culture and communication, Version } 1 \text { is better } \\
\text { al text and in embodying the translation principle of "multi-dimensional } \\
\text { lation method of } 3 \text {-dimensional transformation (i.e. linguistic, cultural and } \\
\text { rsion } 1 \text { fully expresses the cultural information in the sour text, so it has a }\end{array}$ \\
\hline
\end{tabular}

In translating soft news, while making an adaptive selection from the cultural dimension, the translator should not only consider the news characteristic of delivering culture information, but the connotation and characteristics of target culture, and the receptive ability of target readers.

3. Interview of translators

The authors interview Translator 2 for the translation process of "Dao Nantong".

Interviewer: What was your plan of adopting translation strategies or methods before translating the passage? What factors did you consider before translating?

Translator 2: I didn't have much consideration. I read the whole passage and then began to translate.

Interviewer: Don't you consider the style of the passage? 
Translator 2: I felt the material had something to do with tourism. It was narrative. (In fact, the researcher had told her that the article was taken from Jinri Zhongguo before inviting her to translate).

Interviewer: Do you think it necessary to translate all the poems and couplets in the article?

Translator 2: Yes, it is necessary to translate all the parts because all of them are important and can not be omitted.

Interviewer: The article describes Nantong, a tourist attraction, and tells some stories about it. You translated almost the whole passage. What do you think of your translation method?

Translator 2: I didn't think so much. I only thought the content of the original text should be translated.

It could be seen that during the translation Translator 2 did not consider news's stylistic characteristics, text function and target readers, and she mainly adapted to the original text. Actually, in translating soft news the adaptation and selection include not only the linguistic, cultural and communicative dimensions but factors such as source text, target language, length of writing, readers, society, communicative channel and client (employer or translation agency). The following dialogue between the researcher and Translator 1 is about the omission method adopted in translation:

Interviewer: Would you tell me why you used the omission method in translating "Dao Nantong"?

Translator 1: Our translation work has its own characteristics. It has a very strong feature of news. We mainly use the adaptation method. Not only do we consider the text and its logic but target readers, such as their receptive ability and cultural background.

Interviewer: You omitted the whole love story between Zhang Jian and Shen Shou in the Haohe section. Don't you think it necessary to translate Shen Shou's works Xuehuan Embroidery?

Translator 1: Our translation has a length limitation, so we have to delete something according to the length of the text.

Interviewer: But you translated the whole love story between Mao Pijiang and Dong Xiaowan in the section of Shuihui Garden. Is it different from the former love story between Zhang Jian and Shen Shou?

Translator 1: Yes. There is only a few contents under the subtitle of "Shuihui Garden" in the original text. If the love story between Mao Pijiang and Dong Xiaowan had been omitted, there would have been nothing left.

Interviewer: You mean the translation method adapts to the original text, right?

Translator 1: Right. We must take the main content of the original text into consideration.

In the translation eco-environment of soft news, the translator adapts and/or selects the target text mainly from the dimensions of communication, culture and language, and in most cases, it is hard to distinguish these dimensions or levels because they are interwoven. What's more, every dimension, every level or every aspect has different contents interwoven and interacted together. Indeed, the soft news translation is a complex adaptation and/or selection activity if other aspects of translation eco-environment are included, such as writers, readers, sponsors, publishers, translation critics and clients (Hu, 2006), which is the "degree of holistic adaptation and selection" of source text and target language required by the target text.

\section{CONCLUSION}

This study shows that the effective translation strategy of soft news is adaptation. Translation method of soft news is based on communicative translation and takes the semantic one as supplement. Translation process of soft news is the translator's adaption to the typically

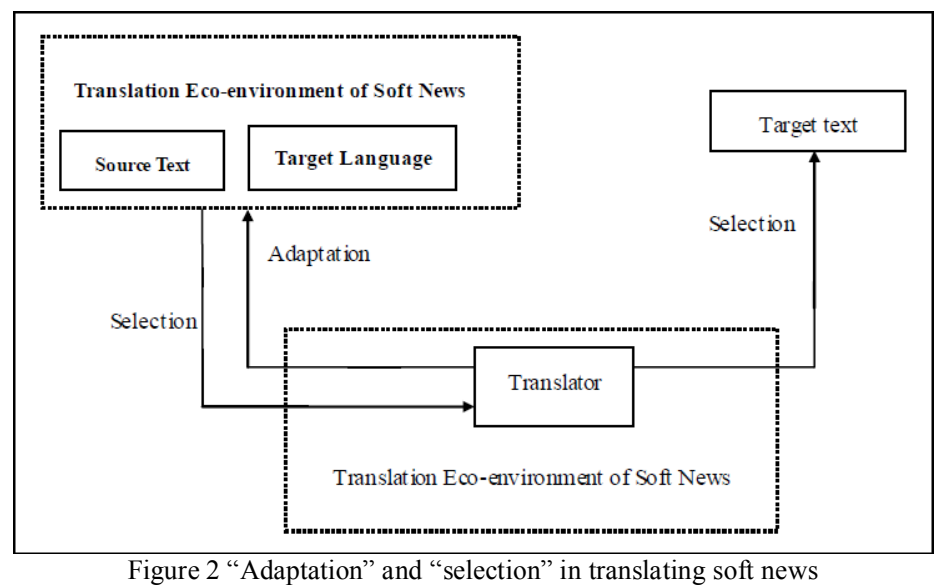

important components of "source text and target language" in one translation eco-environment and the selection of target text made by the typically important component of "translator" in the other (see Figure 2). The only distinction between Figures 1 and 2 is that the first translation eco-environment in Figure 1 takes the source text as a typical component while that in Figure 2 both the source text and target language as typical components. The translation eco-environment of soft news includes sub-eco-environment of source language and that of target language, and the translator bridges the two. The translator of soft news does his or her work mainly in the latter sub-eco-environment and 
so he or she is greatly influenced by the latter. Wang \& Wu (2009) also have the same opinions. The translator makes a selection in every aspect of soft news translation activities, at every stage of translation process and on every level of transformation; a better communicative effect could be achieved in case that the translator makes an adaptive selection considering source text, target language and target readers. News translators' experiences, comprehension of source text, knowledge of text function, etc. have great effects on their translation thought and their choices of translation strategies. There is a correlation between the "degree of holistic adaptation and selection" of soft news translation and the "recognition degree of readers". A better version has a higher "degree of holistic adaptation and selection" and a higher "recognition degree of readers".

\section{REFERENCES}

[1] Fang, Xingfu. (2006). Editing in Soft News C-E Translation. Journal of Sichuang Normal College 6, 64-67.

[2] $\mathrm{Hu}$, Genshen. (2004). The Approach to Translation as Adaptation and Selection. Wuhan: Hubei Education Press.

[3] Hu, Genshen. (2006). Translation Principles and Methods Exemplified for the Approach to Translation as Adaptation and Selection. Foreign Languages and Their Teaching 3, 49-52.

[4] Hu, Genshen. (2008a). Eco-translatology: A Primer. Chinese Translators Journal 6, 11-15.

[5] Hu, Genshen. (2008b). The General Survey of the Approach to Translation as Adaptation and Selection from the Perspective of Terminology. Shanghai Journal of Translators 2, 1-5.

[6] Huang, Youyi. (2004). Insist on the "Three Close Principles of Translation in International Communications", and Properly Deal with the Difficult Points in Them. Chinese Translators Journal 6, 27-28.

[7] Lu, Weizhong. (2002). On the Role of Context Restriction to the News Translation of Periodicals. Shanghai Journal of Translators for Science and Technology 2, 15-18.

[8] Newmark, Peter. (2001). A Text Book of Translation. Shanghai: Shanghai Foreign Language Education Press.

[9] Wang, Yuping \& Wu, Zhijie. (2009). More Than Natural Selection in Translation Studies: A Discussion with Professor HU Geng-shen. Journal of Sichuan International Studies University 4, 135-138.

[10] Wu, Meiling. (2009). Travel to Nantong. China Today, 6, 74-77.

[11] Wu, Meiling \& Li, Zhuoxi. (2009). Dao Nantong—Tingba Jiangsheng Ting Haisheng. Jinri Zhongguo 6, 76-79.

[12] Xu, Quan \& Wang, Ting. (2001). Methods in Soft News Translation and Its Rationale. Language and Translation 3, 39-42.

Wenpeng Lü was born in Gansu, China in 1966. She received her M.A. degree in linguistics from Northwest Normal University, China in 1999. She is currently an associate professor and M.A. supervisor at College of Foreign Language and Literature in Northwest Normal University, China. Her research interests include linguistics and translation studies.

Fuxin Ma was born in Gansu, China in 1977. She received her M.A. degree in translation studies from Northwest Normal University, China in 2011. She is currently a teacher at College of Foreign Language and Literature in Tianshui Normal University, China. Her research interest is translation studies.

Jing Wang was born in Gansu, China in 1984. She is a postgraduate admitted in 2009 by the College of Foreign Language and Literature in Northwest Normal University, China. Her research interest is translation studies. 